\title{
Transformation of communication policy of Slovak companies
}

\author{
Robert Vilagi ${ }^{1, *}$, Michal Konecny ${ }^{2}$, and Frantisek Pollak ${ }^{1}$ \\ ${ }^{1}$ University of Economics in Bratislava, Faculty of Business Management, Dolnozemská cesta 1/b, \\ 85235 Bratislava, Slovakia \\ ${ }^{2}$ Institute of Technology and Business, Faculty of Corporate Strategy, Okružní 517/10, 37001 České \\ Budějovice, Czech Republic
}

\begin{abstract}
Innovation is a major accelerator of development. This is no different with regard to innovations in business management processes. The communication policy of business entities has been undergoing a transformation for more than two decades, where more and more emphasis is being placed on interactive forms of presentation, with which companies can better target selected markets. The aim of the study is to describe selected characteristics of the Slovak market in the light of the transformation from off-line to on-line. Through the analysis of secondary information sources, it is possible to state that on the Slovak market we record both a continuous increase in the share of social network use by companies, as well as an increase in expenditure on Internet promotion. The presented study maps the period until the outbreak of the COVID-19 pandemic, thus creating a reference framework for subsequent research into the effects of the pandemic on the communication activities of Slovak companies.
\end{abstract}

Keywords: innovations; communication; Internet; Slovakia; competitiveness

\section{Introduction}

The transition from off-line to on-line environment can be monitored both on the part of customers and on the part of companies. This shift has a dominantly communicative character, where more and more interactions take place in the virtual world [1-3]. To a large extent, this evolutionary phenomenon can be attributed to the rapid onset of social networks in the first half of the zero years of the new millennium [4-5]. Technology in the form of tablets and smartphones, together with an increasingly available data infrastructure, has offered people a choice where comfort, or rather convenience, has significantly modified common patterns of behavior [6]. Part of the market adapted relatively quickly to changing circumstances, part of the market was skeptical about new trends [7-8]. The process of adopting innovation in any form goes through the usual procedure, which takes the form of a Gaussian curve [9]. At the beginning, there are enthusiasts and innovators who in principle

\footnotetext{
${ }^{*}$ Corresponding author : robert.vilagi@euba.sk
} 
adopt any novelty, it is not a rule that innovation will be accepted by the general public, but if it does, it passes to the called early adopters. Due to its number, it is a significantly larger group than the group of early enthusiasts. At this stage, the chance that the mainstream dominant groups will also innovate increases. At this stage, Slovak societies were in the first half of the first decade of the new millennium [10]. The mainstream began to learn the basic procedures of online communication, where both users and content producers approached the possibilities offered by the Internet with a certain degree of caution [11-12]. The second decade of the twenty-first century fully accelerated the deployment of online solutions in almost every aspect of communication [13-15]. From the point of view of accepting innovations, we have moved to the phase where these innovations began to be adopted by late adopters. The end of the decade was held in a relatively lethargic atmosphere, where most mainstream businesses were fully saturated with their digital needs. The beginning of 2020 subsequently examined the genesis of the integration of digital communication tools into the corporate portfolio in full [16-18]. The COVID-19 pandemic and the associated closure of the economy have changed practices almost from day to day in almost every aspect of life. The Internet has become a necessity for business entities, and to be online was for most of them an elementary determinant of market survival. Before the relevant data are available, we decided to examine the extent to which Slovak companies have mastered online approaches in business until the outbreak of the global pandemic. Our goal is to create a reference knowledge base for subsequent in-depth research. Before proceeding to the presentation of selected characteristics, we will briefly describe selected perspectives of the topic as such

\subsection{Slovak companies and online communications}

Today's world of technology offers companies increasingly accessible opportunities for promotion, while technologies help to create a more competitive environment as such [1920]. Effective promotion tools are no longer the prerogative of the "rich and big", the focus is on the direct struggle for the customer and the most efficient use of resources. The issue of available resources in the form of funding for promotion is partially losing relevance. Social networks have created a highly competitive environment where the effort made does not necessarily equal the financial resources expended.

Kotler [21] argues that advertising aims to convince the customer of the reason for procuring a particular good or service, while sales promotion aims to motivate the customer to make an immediate purchase.

The simplicity of the promotion of goods or services creates a rapidly growing market flooded with offers and promotional materials from various entities. A mix of goods and services along with a mix of industries.

So how to attract a customer? On this issue, companies turn to marketing agencies and thus support the creative, which has found application in the digital age in almost every industry. There is no validated concept. Quantitative indicators in the online world usually do not play such a significant role, the number of addressed customers does not automatically bring economic benefits. At this point, we asked ourselves the initial question:

To what extent is the Slovak market saturated from the point of view of the Internet and the possibilities that the Internet offers to companies?

\section{Objectives and methods}

Starting from the main research question, the aim of the study is to describe selected characteristics of the Slovak market in the light of the transformation from off-line to on-line. By decomposing the main goal, we move on to the partial goals of our study, specifically, 
we focused our efforts on examining the extent to which Slovak companies had in the second decade of the twenty-first century.:

- internet access,

- own website,

- active use of social networks.

We also considered it important to find out to what extent companies were willing to invest in online promotion during the period under review. As part of the comparison, we proceeded to the analysis of formats outside the promotional mainstream, represented by dailies and television. The mentioned media record a long-term declining trend in terms of readability or viewership, but nevertheless represent the first choice in terms of communicating "traditional" content. For the purposes of our analysis, we have chosen to compare the following media:

- Internet,

- Cinema,

- Outdoor,

- Radio.

From the point of view of information sources, we drew both from the available professional literature, as well as available databases and relevant data of the Statistical Office of the Slovak Republic [22]. The data were supplemented by data on the state of the media market, which were available in the form of infographics from renowned media agencies [23].

From the point of view of the observed period, we used the available data, where the time frame of data represented the years 2017 to 2020 for the data of the statistical office, respectively the years 2018 to 2019 for the data of the selected media agency. The data were collected in the months of March to April 2021. The presented data represent the state of the market in the most up-to-date form from the point of view of available data.

From the point of view of the scientific methods used, we have chosen analysis and synthesis as the main scientific methods. The analyzed connections were decomposed and selected, thoroughly analyzed and subsequently synthesized into graphic and textual form. Illustrations describing the state of the analyzed market are also discussed, in order to interpret the context to a wider professional audience.

Data were processed using the MS Office suite, visualization was performed using an MS Excel spreadsheet.

\section{Results and discussion}

The Slovak market offers companies a relatively wide portfolio of opportunities for promotion. If we looked at the issue chronologically, the main condition for online promotion of the company is access to the Internet. Of course, we can also use outsourcing, but there is little assumption that something like the overall corporate identity should be outsourced without Internet access. In Slovakia, more than 95\% of companies are connected to the Internet. This fact expresses the overall availability of the Internet connection throughout the territory. However, availability does not necessarily reflect quality. Despite this fact, availability is a determinant of quality, when without the availability of a service, any quality is only a hypothetical. The following figure presents the total share of companies with Internet access: 


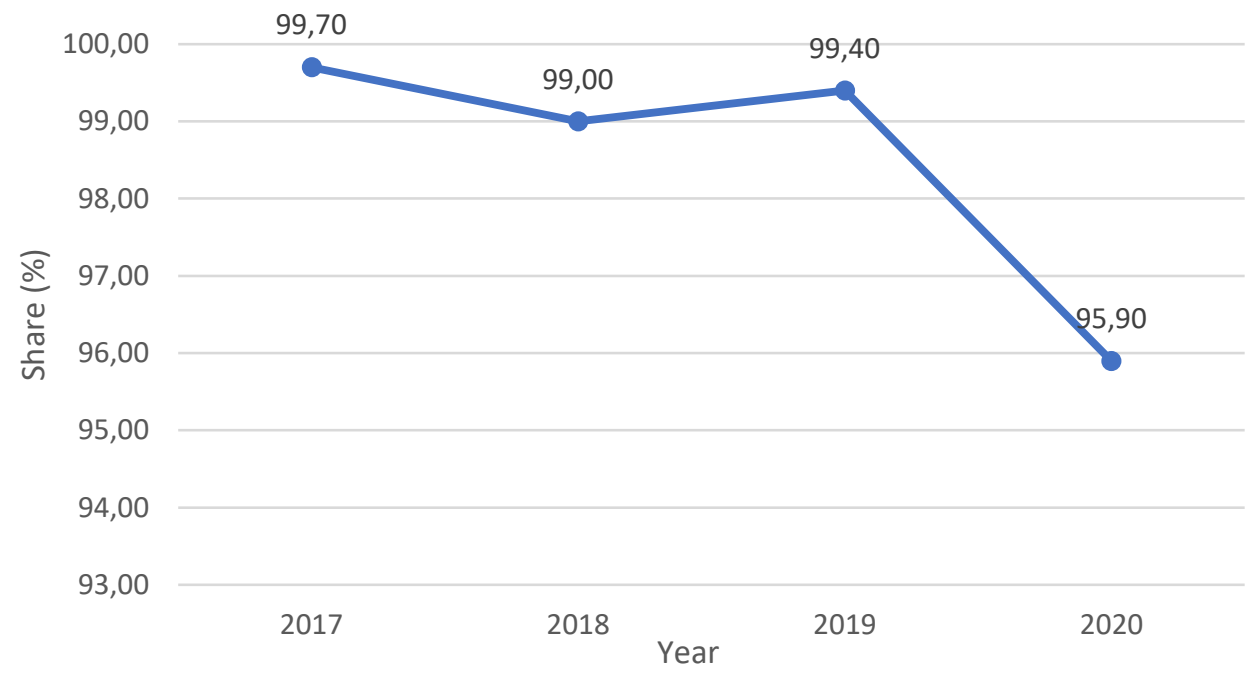

Figure 1. Share of companies with internet access. [22]

One of the initial steps in creating an online communication policy is to create a website. This essential form of communication represents the initial view of society as such. Apart from the industry, it is necessary to have a certain starting point where the customer will find authentic and targeted information about the activity and the offer. Almost $80 \%$ of Slovak companies have this form. The following figure provides an overview of trends within the period under review.

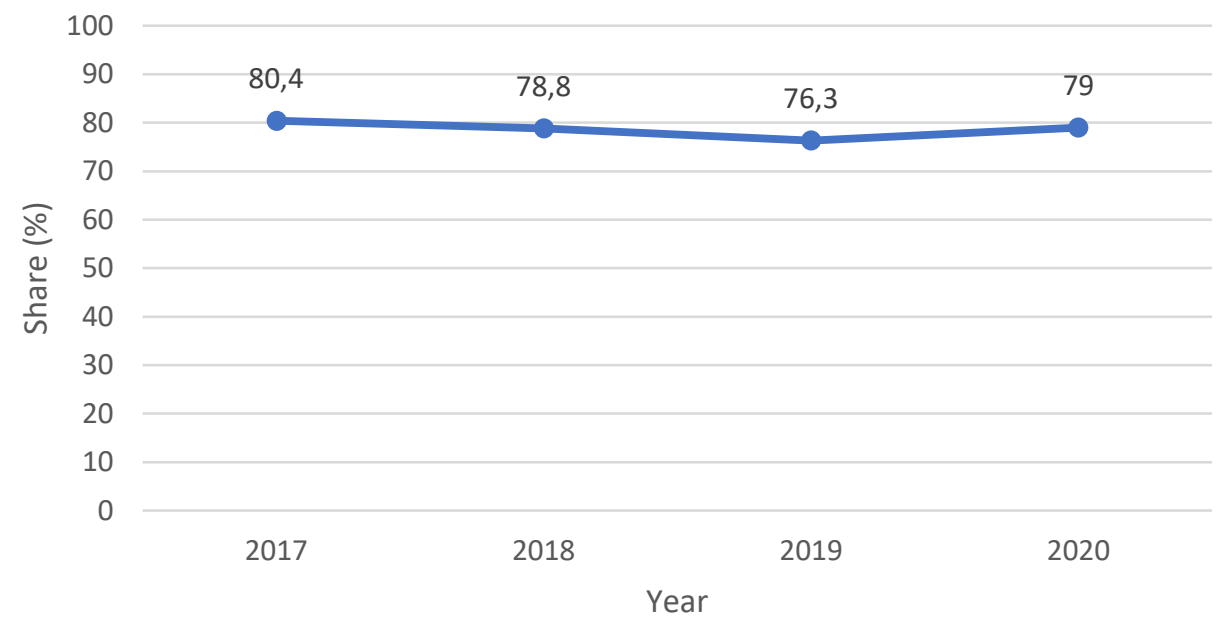

Figure 2. Share of companies with website. [22] 
As far as social networks are concerned, from the point of view of the previous parameters, in this case we encounter a relatively sophisticated quantity. Social networks as a medium offer stakeholder a space for direct contact. They also generate data that companies can use to improve their public relations strategy. The motivation of organizations not to use this form of communication can be different. In the case of manufacturing companies or companies in heavy industry, we encounter this form of active non-participation most often. At first glance, networks such as Facebook and Twitter are not at all interesting for companies in the given industries. However, upon a deeper examination of the possibilities, we discover a portfolio of possibilities and motivations for active use. Whether it is regular or crisis communication, internal PR, or strengthening corporate identity in general, research suggests [24-25] that a transparent and open approach is a way to minimize reputational threats. The following figure shows the share of social network use in the monitored market.

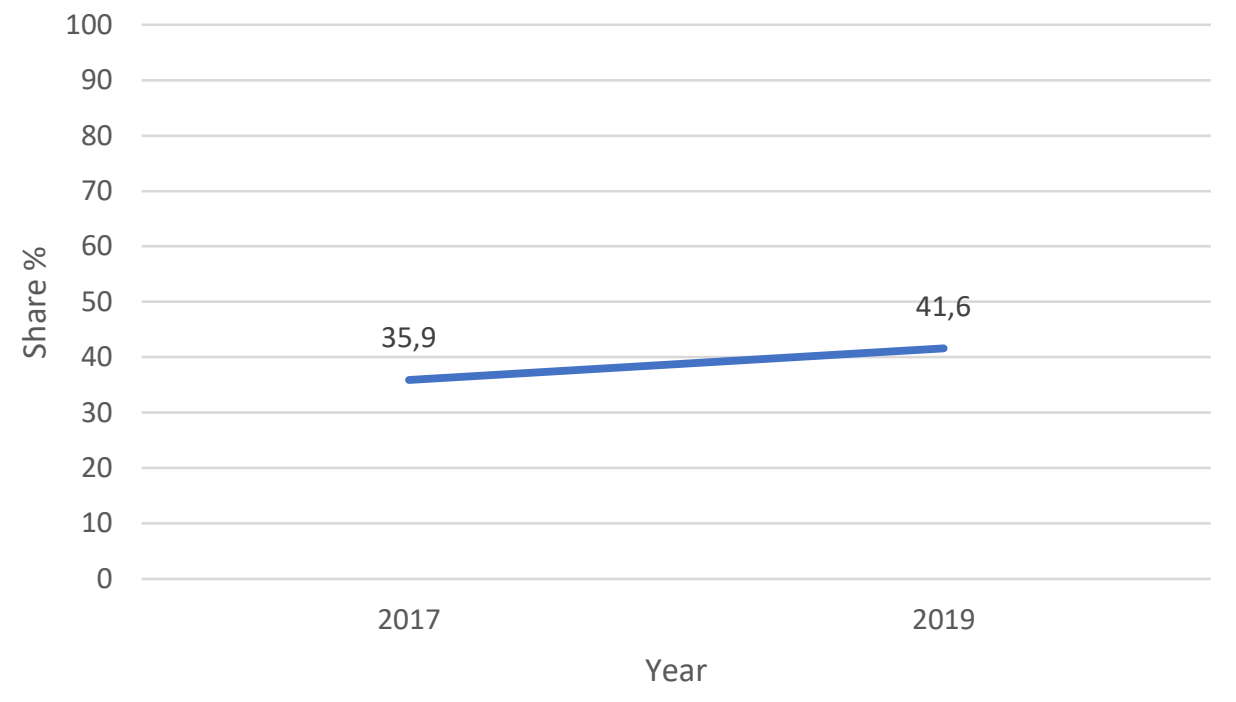

Figure 3. Share of companies with website. [22]

Within the last of the points of the sub-goals defined by us, we will proceed to the presentation of data on the activity of companies within the communication mixes. From the point of view of marketing communication expenditures, companies predominantly use traditional media as a carrier for their target audiences. To a certain extent, this action is rational, especially if we consider the dominantly passive form of such spread messages. Mainstream media such as television and print are a good way for companies to communicate with their market for more than five decades. Therefore, the use of these communication media is a kind of secure game. At this point, it must be stated that mass and unaddressed targeting is in principle ineffective in the hyper information period. From the point of view of the demand side of the market, this fact is confirmed on a daily basis by the continuously declining trend in viewing and reading of traditional media. Media players are well aware of this fact, which is why they are trying to package their offer of media space in various ways. They are increasingly integrating the Internet into their portfolio of services. Ultimately, these facts are also beginning to be understood by companies of traditional thinking, under the pressure of circumstances they are relatively reluctant to change their long-standing and established practices. The following figure presents a shift in spending on selected communication media outside the traditional media stream. 


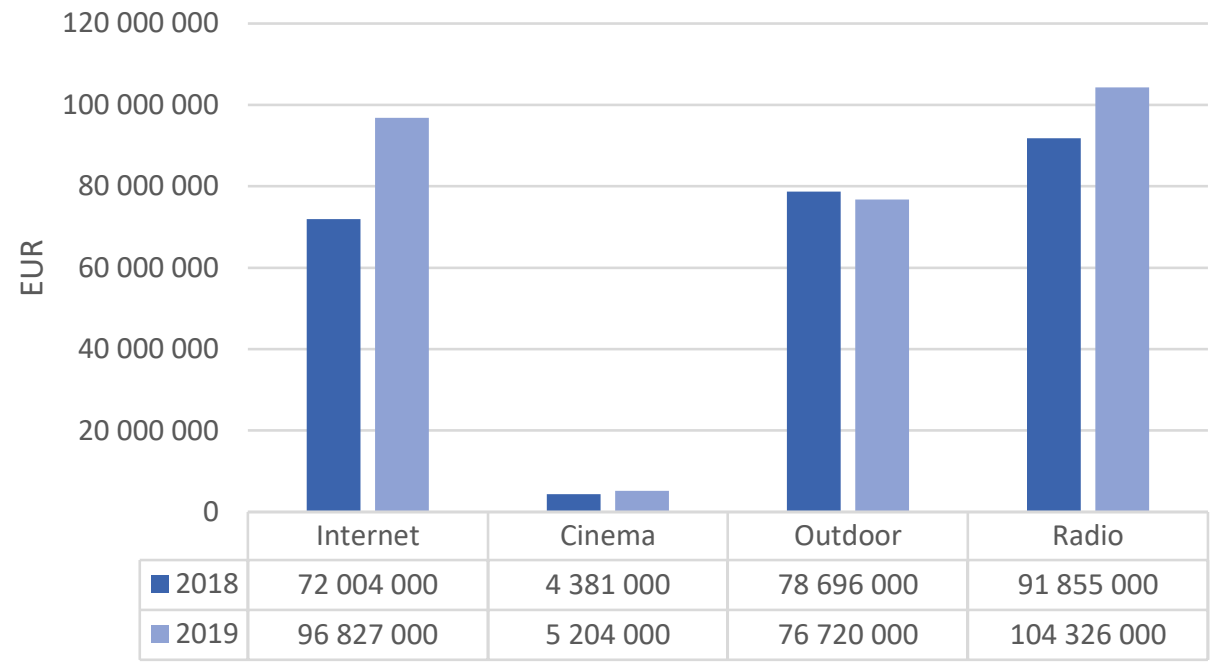

Figure 4. Shift in trends of expenditure on advertising. [23]

As can be seen from the figure, the Internet as a medium record the highest year-on-year growth in terms of companies' advertising spending. This trend only reflects the general state of the market, which we observe in almost all developed economies.

\section{Conclusions}

The income of each media is largely made up of advertising. Television as such is at the forefront of communicating messages to the market. In this case, customers are often placed in the role of passive consumers of media content. This media space is also the most expensive for advertising. In terms of spending on this promotion type, we come to numbers that are well above all other media. Internet advertising as a form of marketing communication is experiencing a relatively rapid increase in terms of numbers. However, it is necessary to take into account the fact that this type of communication medium places much higher demands on the consumer / user. He is no longer a passive recipient of content, but an active participant and co-creator. From the point of view of the future genesis of the market, it is possible to assume a further continuous increase in the level of online communication via the Internet. It is also possible to assume an increase in the availability of technologies for both the supply and demand side of the market. From the point of view of customers, the Slovak internet market shows the parameters of partial saturation, a jump change and an increase in users cannot be expected. As regards the supply side of the market, market saturation can be expected, but this will be preceded by a continuous growth. From the point of view of advertising expenditures, it is possible to assume that the transition from off-line to on-line will continue. Budgets will be reallocated towards customers, which will lead to increased communication targeting and increased efficiency. An overall increase in the competitiveness of proactive and pro-digitally oriented entities can be expected. The extent to which these facts will be affected by the COVID-19 pandemic is questionable at this time. The market needs to be monitored.

Due to the high dynamics of the market, it is assumed that the research of the topic will continue in the form of a subsequent empirical study performed on a significant sample and data in order to compare the state before and after the pandemic. 
From the point of view of the main limitations of the study, it is necessary to mention the dominant regional form of the data, as well as the limited time frames of data within the analysis. The study presents the initial phase of research of the impacts of a pandemic on the national economy.

The article is an output of research project VEGA (1/0240/20) "Financial Aspects of Sustainable Business - Enterprise Succession Solution for Small and Medium-sized Enterprises".

The article is an output of research project VEGA (1/0140/21) "Research on economically important factors of corporate reputation in the context of sustainable industry and low-carbon economy".

\section{References}

1. D. Chaffey, Digital marketing. London: Pearson (2015)

2. M. Bodiš, Procesy elektronického obchodu. Trendy v podnikani 4, 4-10 (2014)

3. R. Čiarniené, G. Stankevičiuté, Theoretical Framework of E-Business Competitiveness. Kaunas. Procedia - Social and Behavioral Sciences 213, 734-739 (2015)

4. M. Zeisser, Unlocking the Exclusive Potential of Social Networks [online]. Available at: http://www.mckinseyquarterly.com/Unlocking_the_elusive_potential_of_social_netwo rks_2623 (2013)

5. G. L. Robins, Doing Social Network Research: Network-based Research Design for Social Scientists. London: SAGE Publications Ltd. (2015)

6. D. P. Clement, Study Finds $80 \%$ of Consumers Shop on Smartphones, M-Commerce Gains [online]. Available at: https://multichannelmerchant.com/ecommerce/studyfinds-80-consumers-shop-smartphones/ (2019)

7. O. L. Turcu, A. Feraru, E-business - A Contemporary Realistic Form Of Successful Business. Economics Edition, "Vasile Alecsandri" University of Bacau, Faculty of Economic Sciences (2013)

8. R. Rajib, Learning more ecommerce and online business. Morrisville: Lulu Press, Inc. (2016)

9. N. Svetozarovova, F. Pollak, Z. Kascakova, The Importance of Key Performance Indicators in the Process of Performance Evaluation of Business Entities Active in the Slovak Republic. Management 2016 - International Business and Management, Domestic Particularities and Emerging Markets in the Light of Research. 177-182. (2016)

10. M.A. Stec, P.B. Filip, M. Grzebyk, Pierscieniak, Socio-economic development in EU member states - concept and classifications. Engineering Economics 25, 5 (2014)

11. J. Soviar, Simplification of Marketing Scheme for Business Start-Ups. Communications - Scientific Letters of the University of Zilina 13, 55-57 (2011)

12. R. Delina, Transparency in Electronic Business Negotiations - Evidence Based Analysis. Quality Innovation Prosperity 8, 79-89 (2014)

13. B. Wierzbinski, Communication and information sharing in the process of creating market advantage among small and medium enterprises collaboration. Hradec Economic Days 2014. Hradec Králové: Gaudeamus, 437-445 (2014

14. D. Zrakova, M. Kubina, G. Koman, Influence of information-communication system to reputation management of a company. 12th International Scientific Conference of Young Scientists on Sustainable, Modern and Safe Transport. Procedia Engineering 192, 1000-1005 (2017) 
15. N. T. Saruc, P. Dorčák, F. Pollák, E-business and its Application in Conditions of Central European Market. QIP journal. 17, 1 (2013)

16. Kalogiannidis, S. Covid Impact on Small Business. International Journal of Social Science and Economics Invention 6, 387-391(2020)

17. Bohn, S., Mejia, M. C., \& Lafortune, J. The Economic Toll of COVID-19 on Small Business. California: Public Policy Institute of (2020)

18. A. Bhatti, H Akram, H.M Basit, A.U Khan, S.M Raza, M.B Naqvi, Ecommerce trends during COVID-19 pandemic. International Journal of Future Generation Communication and Networking 13, 1449 - 1452 (2020)

19. F. Pollak, P. Dorcak, Analysis of online reputation of elected e-commerce entities operating in the central European market. IDIMT-2015: Information technology and society - interaction and interdependence: 23nd interdisciplinary information management talks. 255-262. (2015)

20. F. Sudzina, P. Kmec, The technological paradox and evaluation of the benefits of informatization. Journal of Economics 54, 281-293 (2006)

21. P. Kotler, et al., Moderní marketing. Prague: Grada Publishing (2007)

22. Statistical Office of the Slovak Republic. IKT v podnikoch. [online]. Available at: http://statdat.statistics.sk/cognosext/cgibin/cognos.cgi?b_action=cognosViewer\&ui.action=run\&ui.object=storeID $(\% 22 \mathrm{iF} 656$ BB5617D94B22872CB96564161686\%22)\&ui.name $=I K T \% 20 v \% 20$ podnikoch $\% 20 \% 5$ bis1003rs\%5d\&run.outputFormat $=\&$ run.prompt $=$ true \&cv.header $=$ false\&ui.backURL $=$ $\% 2$ fcognosext $\% 2$ fcps $4 \% 2$ fportlets $\% 2$ fcommon $\% 2$ fclose.html\&run.outputLocale=sk (2020)

23. Kantar. Ako sa vyvíjali výdavky do reklamy v 2019. [2020]. Available at: https://www.kantarmedia.com/sk/blog/infografiky/ako-sa-vyvijali-vydavky-doreklamy-v-2019 (2020)

24. P. Dorčák, P. Markovič, F. Pollák, Multifactor analysis of online reputation as a tool for enhancing competitiveness of subjects from automotive industry. Journal of Economics 65, 173-186 (2017)

25. M. Fertik, D. Thomson, Wild West 2.0: How to Protect and Restore Your Reputation on the Untamed Social Frontier. New York: Amacom (2010) 